Article

\title{
Simulating the Evolution Mechanism of Inner Innovation in Large-Scale Construction Enterprise with an Improved NK Model
}

\author{
Tao Chen ${ }^{1,2, *}$, Guangqiu Huang ${ }^{1}$ and Ayokunle Olubunmi Olanipekun ${ }^{3,4}$ \\ 1 School of Management, Xi'an University of Architecture and Technology, Xi'an 710055, China; \\ luqiuqin@xauat.edu.cn \\ 2 Planning Department, Xi'an Shiyou University, Xi'an 710065, China \\ 3 Quantity Surveying Department, Federal University of Technology, Akure PMB 704, Nigeria; \\ AyokunleOlubunmi.olanipekun@hdr.qut.edu.au \\ 4 School of Civil Engineering and Built Environment, Queensland University of Technology, \\ Brisbane 4072, Australia \\ * Correspondence: ghc@xsyu.edu.cn
}

Received: 1 October 2018; Accepted: 9 November 2018; Published: 15 November 2018

\begin{abstract}
The aim of this study is to simulate the self-organized evolution mechanism of inner innovation of large-scale construction enterprises (LSCE) under different contexts. Based on NK stochastic combinatorial optimization model with two parameters $(\mathrm{N}, \mathrm{K})$, this study proposes three modules-ambidexterity, punctuated equilibrium, and automation - to simulate the change behaviors of the inner innovation system. Furthermore, this study analyses the influence of factor correlation on inner innovation performance under discusses nine different combination situations. The research results show that (a) regardless of how the relationship strength changes, fitness increases with an increasing $\mathrm{K}$ value; and (b) the comparison of optimization modes show that the punctuated equilibrium mode can guarantee the long- and short-term inner innovation performance LSCE. This study therefore reveals the mutual effects of the factors in the inner innovation system in LSCE and provides an effective model for internal systems analyses in the construction industry and in other sectors.
\end{abstract}

Keywords: enterprise management; inner innovation optimization; simulation; NK model; construction enterprises

\section{Introduction}

In recent years, the adjustment, transformation, and upgrading of economic structure as well as the development of both the service economy and the open economy has increased the use of the enterprise group among the enterprises engaged in commercial mode of operations, management, and innovation [1,2]. In the enterprise collectivization process, it is important for problems such as resource arrangements for the parent-subsidiary corporation, financial management and multi-objective resource allocation to be appropriately managed $[3,4]$. Therefore, the large-scale construction enterprises (LSCE) need to pay attention to enhancing their inner innovation to reduce innovation risk, enhance overall competitiveness, innovation benefits, and stability $[5,6]$; and promote rapid and stable development $[7,8]$.

Reforms and developments of inner innovation within enterprises have recently increased in response to national economic development drives in many countries [9]. For instance, the central committee reform in China pointed out that a mixed ownership form of economic development should be encouraged, and enterprise reform should be deepened [8]. As a result, emphasis on reforms has 
shifted to the LSCE Generally, the construction industry is an important industry in any national economy that contributes to national economic growth, job creation, infrastructure provision and social stability [10]. Within the construction industry, the LSCE are enterprise leaders in constant mode of transformation and structural adjustments [11]. Consequently, the LSCE are notable for enterprise activities such as resource reconstruction, industrial structure optimization, research and development, environmental governance, and industrial modernization [12]. Moreover, regular debates on the inner innovation of the national economy suggests the need for more emphasis on the inner innovation in LSCE, especially at the micro level [13].

Consequently, research on the inner innovation of enterprises, especially from the perspectives of self-organized and complex systems is very extensive [12-15]. In the construction industry, these include the analysis of the self-organized coupling network function relationship for the inner innovation based on the self-organization theory, establishing the self-organized cooperative evolution model of the inner innovation system and the analysis of the cooperative evolution of the enterprise inner innovation [13]. Particularly, the inner innovation in LSCE is very complex due to their large scale $[16,17]$. According to [14], complex systems are characterized by conflicting constraints due to the interdependencies between the constituting elements. The constraints often lead organizations to lock-in into local optima on a rugged fitness landscape [14]. Within LSCE, the complexity is reflected in the mutual relationships among the internal factors in the system [18]. However, with the complex nature of the LSCE, there is no research on exploring the inner innovation and the interactions among the elements of the inner innovation in LSCE. Thus, the self-organized evolution mechanism in LSCE is unknown.

To fill the gap in knowledge, the aim of this study is to employ the NK model of complex evolving systems to analyze/explore the self-organized evolution mechanism of the inner innovation system in LSCE. According to [15], the NK model is a stochastic combinatorial optimization model with two parameters $(\mathrm{N}, \mathrm{K})$ for studying innovation. As this study is focused on exploring the inner innovation in LSCE, $\mathrm{N}$ is the components of the inner innovation system, while $\mathrm{K}$ is the interaction or epistasis among them. The complex and non-linear interaction between different internal factors of the enterprise inner innovation system promotes the system to a higher-level status. This type of self-organized evolution process from a low level to a higher level is similar to the constant evolution of the living body to adapt to the external environment. Therefore, the approach in this study aligns with the fitness landscape bionic theory.

The contributions of this study are as follows. First, the application of the NK model for the analysis/exploration of the enterprise inner innovation in construction enterprises is a first. Second, this study considers the new context of unordered alternation between individual (group) variation and continuous local adjustment by integrating ambidexterity with the punctuated equilibrium hypothesis. As a result, this study proposes the innovative spiral model to reflect this alternation. The new context of factor variation systematically and comprehensively reveals all non-linear relationships between factors. Furthermore, it allows analysis of the interaction strength and relationships between different factors in the self-organized evolution process of the enterprise inner innovation in large-scale construction enterprises.

The structure of this study is as follows. The Section 2 comprises of literature review of the application of the enterprise inner innovation and NK model in enterprise management. The Section 3 introduces the NK model, proposes the relationship strength coefficient to adjust $\mathrm{K}$ and the three types of optimization methods. The Section 4 shows the simulation results, including a comparison between fitness landscape pictures, individual fitness and three types of optimization as well as an analysis of the local and overall optima. The Sections 5 and 6 are the discussion and conclusion, respectively. 


\section{Literature Review}

\subsection{Research on the Enterprise Inner Innovation}

Open innovation suggests that firms may use either external or internal ideas, or internal and external paths to market and generate additional value [16]. According to [17], there are four bounds of open innovation that when combined, shapes enterprise performances. Firstly, the revealing one is when internal resources are revealed to the external environment. Secondly, the selling one is when firms commercialize their inventions and technologies through selling. It could also be licensing out resources developed in other organizations. Thirdly, the sourcing one is how firms can use external sources of innovation, while the last one is acquiring, which is acquisition of input to the innovation process through the market place. At the firm level, West, J revealed the challenges to the application of open innovation including finding means to innovate internally, embedding external innovation into internal development and encouraging outsiders to supply an ongoing stream of external innovation [18]. To overcome these challenges, firms should engage in research and development cooperation, transform internal projects to externally visible open-source projects, selling, and attracting donated complements [18]. As industrial innovation is becoming more open, business enterprises, new technologies need to make changes to the metrics for managing innovation to be able to limit false positives and reduce false negatives. According to [16], such metrics include outputs of open innovation process, time to market for new products and services, incidence of false-negative projects and the progress of potentially false-negative projects.

There are few research achievements on national economic control. Some of the famous internal control models in organizations are COSO (The Committee of Sponsoring Organizations of the Tredway Commission) of America [19], Cadbury of Britain [20]. The internal control models are used for the analysis of the operational activities in enterprises from different perspectives and consequently, provide suggestions for establishing a good internal control framework [21]. The internal control evaluation system of Chinese enterprises is primarily composed of "Guidance to Enterprise Internal Control Evaluation" [22] and "Guidance to Enterprise Internal Control Audit" [23]. These systems offer only qualitative analyses of the effectiveness of internal controls and provide a basic framework for establishing an enterprise internal control evaluation system.

Different factors are necessary for selecting evaluation indicators for the enterprise internal inner innovation. According to Xia [21], these factors provide a foundation and a basic standard in listed companies to formulate internal control indexes. In the opinion of Chen [24], the internal control indicator system is mainly used to measure the perfectness of the internal control system. Meanwhile, to carry out such measurement, it is necessary to have a set objective and a scoring basis [25]. Industrial cluster is customary to innovation. In the developing country context, Yunfei Shao identified the factors that promote innovation In the Chengdu industrial cluster in China [26]. These include competition effects, cluster learning, spill over and diffusion and incentives in the cluster. Except for spillover and diffusion, the factors enhances the innovativeness in the cluster. Furthermore, innovation in industrial clusters can be increased through the networking of firms within the clusters. Networking promotes both collaboration and collective learning for sustaining innovation [27]. Additionally, Lijuan Du suggests that technological enterprises should get new technology through cooperation [28]. QIN Zhi-hua's studies contrasted between innovation in enterprises in both mature and immature markets [29]. In the former, innovation is akin to frequent product updates and increasing market share. In the latter, due to unstable environment, innovation is akin releasing new products to appeal to potential customers.

In China, many enterprises are reducing dependence on foreign innovation, while attempting independent innovation. According to [28], independent innovation has been challenging due to low awareness, shortage of financial support, and lack of talented innovators. To improve the capacity for independent innovation in China, the government should facilitate merger among smaller enterprises, increase financing for independent innovation and increased cooperation between enterprises between 
enterprises and universities and research institutes [28]. According to [29], investment in research and development within enterprises is a strategic option that ignites employees' initiative and creativity to innovate.

For innovation to translate to sustained competitiveness, enterprises need to make trade-offs between competing demands, for instance, whether to invest in either current or future projects. As pointed by Gibson, successful enterprises that can manage competing demands are ambidextrous [30]. Additionally, ambidextrous enterprises have a coherent pattern of activities that can easily be reconfigured to meet demands in the enterprise environment. In ambidextrous enterprises, the interaction between explorative and exploitative innovation strategies leads to sales growth, while an imbalance between both strategies leads otherwise [31]. The explorative strategy supports a more disruptive innovation while the exploitative strategy supports conservatism in innovation taking. It is better to integrate both explorative and exploitative strategies for sufficient innovation within enterprises [31].

The evaluation of the inner innovation in enterprises is most often carried out using mathematical methods, such as factor analysis [32] and fuzzy evaluation methods [33]. These mathematical methods enable the selection of multiple indicators, establishes a corresponding internal control evaluation system, assigns weights to indicators through expert scoring and evaluates the internal inner innovation level. For instance, Wangfeng [34] employs the basic standards of enterprise internal control" as the basis to select 25 evaluation indicators to establish the internal control evaluation system. Furthermore, Wentao and Weian [35] used the decision information demand of external stakeholders to select a multi-layer fuzzy comprehensive evaluation model based on AHP (Analytic Hierarchy Process), form the internal control quality evaluation criterion, and establish a comprehensive evaluation model of enterprise internal control. Meanwhile, stochastic models such as the NK model have more advantages than the mathematical ones for the evaluation of inner innovation in enterprises. According to $[14,15]$, these advantages are: firstly, the NK model has better internal effectiveness and is suitable for researching vertical and non-linear processes. Secondly, it can be used to investigate the influence of environmental features on search behavior by constantly changing the fitness landscape; therefore, in a complex and volatile environment, the NK model is more feasible and concise than empirical research methods. Thirdly, compared with other computer simulation methods, the NK model can be used to investigate the search behavior of multiple subjects; therefore, it can be used to observe the influence of the self-organized behaviors of microcosmic subjects on macroscopic emergence and to observe the entire process of macroscopic emergence clearly through the simulation process. Fourthly, it can dynamically analyze the performance influence of $\mathrm{N}, \mathrm{K}$, and the relationship strength changes on the LSCE inner innovation.

Li Changhong examined the mutual effects mechanism of technology spill over in cooperation and enterprises' innovation competence and consequently developed a cooperative technology innovation model using the multi-agent system [36]. The multi-agent system was used for its ability to solve complex problems and identify cooperation in a system. The developed model reveals that the innovation competence in the enterprises increased by the level of cooperation technology spill over in Multi-Agent cooperation system. Jiang Wei's conceptual model can be used to evaluate the amount of networking in an innovation process [27]. It comprises communication with different actors, speed of product innovation and innovation performance. Similarly, the Lijuan Du's scientific models of innovation is useful for enterprises seeking independent innovation [28]. The models can enhance re-innovation after technology importation. Both the studies of $[37,38]$ emphasize on the triple helix as a model of innovation. The triple helix comprises of the university-industry-government relations and the transformation processes among them leading to innovative activities. According to [38], there are three forms of the triple helix model. The first one envisages the university, industry, and government as institutions. The second one is that the university, industry, and government have different communication systems. The third one is that each of the university, industry, and government can assume each other's role in an innovation process. Finally, Tim Padmore identified the important characteristics of an effective model of innovation [39]. Firstly, the model should be flexible for use in different sectors, places, and times. Secondly, the model 
should be simple for easy discussion among policy makers and experts. Thirdly, the model should be quantifiable and subjective to testing and policy-weighting.

Summarily, research on inner innovation in enterprises can be categorized into those: identifying the indicators of inner innovation in enterprises, evaluating inner innovation in enterprises, and developing evaluation models for inner innovation in enterprises. These research areas focus on organizations in the technological, manufacturing, and industrial sectors. None is focusing on inner innovation in the construction industry. This study will employ the NK model to simulate the inner innovation in LSCE.

\subsection{Application of the NK Model in Enterprise Management}

Based on fitness landscape theory [40], Kauffman [41] created a structured simulation model in 1987, the NK model. The model assumes that a specific specie has $\mathrm{N}$ genes and each gene is affected by $\mathrm{K}$ genes, then the range of $\mathrm{K}$ is $0 \leq \mathrm{K} \leq(\mathrm{N}-1)$. The mechanism behind this model is the complexity of mutual influence and interaction between internal factors and achieves the optimal point rapidly and effectively through fitness research. Consequently, the NK model has been widely applied in the economics and management fields for researching complex system structure and the internal interactions of system [42].

The focus of the existing static research, based on the hypothesis of a linear relationship between continuously driven factors, is limited to the size and direction of the routes obtained from application experience data without further deep analysis of future development trends and the possible results of a driven route based on experience data [43-46]. For example, Auerswald and Kauffman [43] established the production technology model based on the NK model. The study employed the internal decision-making activities of enterprises as possible combinations of all decision-making activities in the complex system and the production process to form decision-making space and adopt the fitness value to simulate routes for enterprise production technology. However, the development and the changing laws of the driven route are not researched.

Franken [44] sought the optimal combination in the search space by aid of the NK model when analyzing product technology innovation but only presented the static result of the optimal route. Xia and Guilong [45] conducted an empirical investigation of 103 provincial-level enterprise technology centers in Guangdong. They adopted the optimization processing of the NK model to analyze and discuss the interaction of innovation management factors. The study revealed the effective channel and methods for enhance enterprise technology innovation performance by aiding fitness, as well as the influence of internal coupling relations on innovation. Thus, the NK model provides organizational economists with a metaphorical form of explanatory framework that combines organizational system evolution and market selection mechanisms [46].

This study views the inner innovation of LSCE as a complex network system with interaction between internal factors. The programming of the evolution process for the inner innovation in LSCE is carried out to establish a related NK model. Within the model, the fitness contribution of a random value combination of internal decision-making variables is distributed randomly. Therefore, the model can realize an analogue simulation of a general complex system that can be used to understand the structure and interaction of a complex adaptive system by analyzing module composition, and the interaction between different factors in terms of its linearity, complexity, and strength. The evolution process for the inner innovation in LSCE is usually taken as a complex network system with interactions between internal factors. The mutual influence and interaction between the service innovation driving factor module, the result module and the overall module in the system is one of the important drivers of system complexity; because these feature nonlinearity and dynamism, it is difficult to obtain effective data for measurement through empirical methods [47].

The inner innovation in LSCE is not affected by a single driving factor but is a complex system comprehensively affected by multiple internal and external driving factors [48], while the interaction between various driving factors belongs to a vertical structure. The NK model serves well to analyze 
the vertical complex system of the inner innovation of large-scale construction enterprises. Meanwhile, constant changes in landscape degree, namely, the different proportions of different driving factors and different objective results, can be helpful in analyzing the influence of different driving factors on the innovation service capability of construction enterprises. Gupta [49] summarizes two modes through which enterprises realize innovation balance: ambidexterity and punctuated equilibrium. The former [50] stresses that the enterprise can conduct exploratory innovation and applied innovation to realize exploratory reform and applied reform in different organization units through spatial separation. It can reduce the conflict between the two types of reforms in terms of resource demand and generate a cooperative effect to better promote enterprise development. The latter [51] stresses that the enterprise conducts these two types of reforms alternately, exploratory reform and then applied reform, in one organizational unit with a time separation; usually, the applied reform takes longer, while the exploratory reform takes less time. This process can prevent resource conflict between the two types of reforms, as the enterprise focuses on one reform behavior to obtain an advantage that is better adapted to the current environment and enhance enterprise performance [52]. This is also synonymous with strategic flexibility within enterprises to appropriately respond to environmental changes in a timely manner taking cognizance to marketplace competition [53].

In this study, the factor variation mode is summarized as ambidexterity and punctuated equilibrium, considering the continuous local adjustment or individual (group) variation, respectively, but without considering the third situation of individual (group) variation and the unordered alternation of continuous local adjustment. However, the third situation exists and should be emphasized, as it is the necessary complement for the above two situations. These three types of factor variation situations systematically and comprehensively reveal all non-linear relationships between factors. Therefore, this research combines the forward spiral model with the above two mode types, namely, the alternation of local adjustment and variation.

\section{Research Method}

\subsection{Analysis Level}

As this study seeks to establish a simulation model of the LSCE inner innovation and to determine the parameters that better suited in actual situations, this section specifies the mode of analysis level employed. The second level indicators are the factors in the simulation model. In addition, the study expands the number of factors in the general NK model. It expands the scope of parameter $\mathrm{K}$ and introduces strength relationship. The latter is better for analyzing the fitness change caused by mutual relations between multiple factors in the system. Furthermore, this study focuses on method innovation in the following ways. First, it uses the analogue simulation of the LSCE inner innovation based on the NK model. Second, it designs the inner innovation optimization methods of ambidexterity and punctuated equilibrium based on the change characteristics of the inner innovation system. Third, it proposes an optimization method characterized by an automatic mode innovation of both ambidexterity and punctuated equilibrium.

Furthermore, the objectives, structures and resources are abstractly taken as a type of complex system with interactions between internal factors. The complexity is controlled by $\mathrm{N}$ number of internal factors and $\mathrm{K}$ interactions of internal factors [54], wherein $\mathrm{N}$ refers to all factors influencing the inner innovation and $\mathrm{K}$ represents the number of $\mathrm{i}$ having relationships with other factors. Theoretically, this is based on the situation of $0 \sim \mathrm{N}-1$. When $\mathrm{K}=0$, it shows that the factors are independent with each other, and when $\mathrm{K}=0 \sim \mathrm{N}-1$, it shows that factor $\mathrm{i}$ has relationships with $\mathrm{K}$ other factors. The complexity of the system will increase with the increase in the $K$ value. When the factors are independent of each other $(\mathrm{K}=0)$, it is called a simple environment; when there is high independence between factors $(K=0 \sim N-1)$, it is called a complex environment [55]; affected by the operation method, thus, K cannot be infinite. The illustration of the LSCE inner innovation based on the NK model and the corresponding parameters is shown in Table 1. 
Table 1. The proposed model for the inner innovation of LSCE based on the NK Model.

\begin{tabular}{ccc}
\hline Parameter & Classic Kauffman NK Model & Proposed NK Model for LSCE Inner Innovation \\
\hline $\mathrm{N}$ & The number of genes in the species & $\begin{array}{c}\text { The number of elements of Inner Innovation system } \\
\text { for large-scale construction enterprise }\end{array}$ \\
\hline $\mathrm{A}$ & Mutual relatives between genes & $\begin{array}{c}\text { The number of correlations between one element and } \\
\text { other elements in the Inner Innovation system }\end{array}$ \\
\hline$\lambda$ & The number of alleles a gene has & $\begin{array}{c}\text { The possible states of each element in the Inner } \\
\text { Innovation system }\end{array}$ \\
\hline Gene strength is equivalent & $\begin{array}{c}\text { The tightness of the links between elements in the } \\
\text { Inner Innovation system }\end{array}$ \\
\hline
\end{tabular}

The LSCE inner innovation system is composed of six aspects: objective level, structure level, resource level, function level, mechanism level and communication level. (See the enterprise inner innovation evaluation indicator system in Section 3 for the factor selection and indicator explanation.) As shown in Table 2, there are 22 influencing factors of the LSCE inner innovation system; therefore, $\mathrm{N}$ is 22 in the proposed NK model of the LSCE inner innovation.

Table 2. Dimensions and influencing factors of the proposed NK model.

\begin{tabular}{|c|c|c|c|}
\hline Dimensions & Influencing Factors & Dimensions & Influencing Factors \\
\hline \multirow{5}{*}{ Goals (K1) } & Resource allocation (N1) & \multirow{4}{*}{ Features (K4) } & Constraint function (N12) \\
\hline & Management decisions (N2) & & Adaptation function (N13) \\
\hline & Product cost (N3) & & Guide function (N14) \\
\hline & product quality (N4) & & Business function (N15) \\
\hline & Financial management (N5) & \multirow{4}{*}{ Mechanism (K5) } & Management mechanism (N16) \\
\hline \multirow{4}{*}{ Structure (K2) } & Organizational structure (N6) & & Talent mechanism (N17) \\
\hline & Capital structure (N7) & & Market mechanism (N18) \\
\hline & Governance structure (N8) & & Incentives (N19) \\
\hline & Market structure (N9) & \multirow{3}{*}{$\begin{array}{l}\text { Communication } \\
\text { (K6) }\end{array}$} & Business communication (N20) \\
\hline \multirow{2}{*}{ Resources (K3) } & Internal tangible resources (N10) & & Emotional communication (N21) \\
\hline & External intangible resources (N11) & & Management communication (N22) \\
\hline
\end{tabular}

Source: Tao et al. (2015) [56].

\subsection{Classic NK Model}

The three main parameters in the classic NK model are N, K and A. In the LSCE inner innovation system, $\mathrm{N}$ represents the number of members, namely, all influencing factors; $\mathrm{N}=22$. $\mathrm{K}$ represents the number of $\mathrm{i}$ having relationships with other factors, considering $0 \leq \mathrm{K} \leq 7$. A represents the number of alleles in each gene. The fitness questionnaire for the LSCE inner innovation system is set to a scale of $5.0=$ very poor, $1=$ relatively poor, $2=$ ordinary, $3=$ relatively good, $4=$ very good. There exist $5^{\mathrm{N}}$ possible combinations, which is represented by a quinary status string. Fitness $f_{i}$ represents the contribution value of factor $i$ to the fitness landscape of the system, which is related to the fitness $x_{i}$ of $i$ and fitness $x_{j}$ of the other $K$ factors, namely:

$$
f_{i}=f_{i}\left(x_{i}, x_{j}\right)(j=1,2, \ldots, N ; j \neq i)
$$

Introduce the intensity matrix and calculate the fitness distance of the individual. The fitness F of the LSCE inner innovation is the sum of the average fitness of the factors:

$$
\mathrm{F}=\frac{1}{\mathrm{~N}} \sum_{\mathrm{i}=1}^{\mathrm{N}} \mathrm{f}_{\mathrm{i}}
$$


When the status string of the system varies, $\mathrm{F}$ is in the optimization process for the feasible space; when the new $\mathrm{F}^{\prime}$ is larger than $\mathrm{F}$, it can be alternated, and otherwise, it can be retained. Accordingly, both the evolution from the local optimum to the overall optimum of the fitness landscape and the process of climbing the fitness landscape can be realized.

\subsection{Specific Description of K by Introducing the Relationship Strength Coefficient}

Relationship strength reflects the closeness between factors. The relationship intensity $\lambda$ specifically describes K. The LSCE inner innovation system is formed based on the mutual coordination of factors. It is presented as an organizational approximation and as a high reliance on platforms, and the organization approximation degree formed based on the platform is relationship intensity. The relationship intensity between factor $i$ and factor $j$ is represented by $\lambda_{\mathrm{ij}}$ [57]. This study adopts contact frequency to measure relationship intensity with a value range of $0-1 . \lambda_{i}$ is the total relationship intensity of factor $i$, and its value is the mean value of the relationship intensity of other factors, while $i$ and its own relationship intensity holds no calculative significance. The calculation Formula [58] is as follows:

$$
\lambda_{\mathrm{i}}=\frac{1}{\mathrm{~N}-1} \sum_{\mathrm{j} \neq \mathrm{i}} \lambda_{\mathrm{ij}}
$$

This formula does not mean that the stronger the relationship intensity is, the better it is; when intensity surpasses a certain limiting value, the inner innovation caused by the intensifying relationship will be restricted by high cost, thus slowing down. Based on this, considering the relationship intensity of the inner innovation, the fitness of factor $i$ is as follows:

$$
\mathrm{f}_{\mathrm{i}}^{\prime}= \begin{cases}\left(1+\lambda_{\mathrm{i}}\right) \mathrm{f}_{\mathrm{i},} & 0<\lambda_{\mathrm{i}}<\alpha \\ \left(1+\lambda_{\mathrm{i}}-\frac{3}{4} \lambda_{\mathrm{i}}^{2}\right) \mathrm{f}_{\mathrm{i}}, & \alpha \leq \lambda_{\mathrm{i}}<1\end{cases}
$$

where $\alpha$ is the tipping point where the fitness of factor i decreases with increasing intensity, and its range is $1 / 3$ [58]. At this moment, the relationship intensity $\lambda$ and the fitness $\mathrm{F}^{\prime}$ of the LSCE inner innovation are the mean values of factors, namely:

$$
\begin{aligned}
& \lambda=\frac{1}{N} \sum_{i=1}^{N} \lambda_{i} \\
& F^{\prime}=\frac{1}{N} \sum_{i=1}^{N} f_{i}^{\prime}
\end{aligned}
$$

The value of relationship intensities influences the fitness of the system, and different relationship intensities form different fitness landscapes. When the relationship intensity is between $[0,1 / 3)$, it is defined as a weak relationship; when it is between [1/3,2/3), it is defined as a strong relationship; when it is between $[2 / 3,1]$, it is defined as a super-strong relationship.

\subsection{Optimization Mode}

\subsubsection{Ambidexterity: Alternation between Change and Variation}

Under the mode of ambidexterity, LSCE divide resources equally to conduct inner innovation change and inner innovation variation because enterprise resources are limited, and each unit needs two simulation periods for one innovation. Specifically, the enterprise completes one inner innovation variation in one simulation period and completes one applied innovation of the inner innovation in the next simulation period. This is represented by the alternation of an exploratory innovation of the inner innovation and an applied innovation of the inner innovation. 


\subsubsection{Punctuated Equilibrium: Variation Based on Multiple Changes}

Under the mode of a punctuated equilibrium, a short period of exploratory innovation and a long period of applied innovation are conducted in one circulation [59]. In the NK model, the enterprise takes $t$ periods for one circulation, exploratory innovation taking $\varepsilon t$ time and applied innovation taking $\mathrm{t}-\varepsilon \mathrm{t}$ time, wherein $\varepsilon$ represents the relative proportion of exploratory innovation accounting for overall innovation. In the model, $\varepsilon=3 / 10, t=10$. When one circulation ends, a new circulation will start, represented by alternation between one exploratory innovation and one applied innovation.

\subsubsection{Automation: The Fitness Never Changes Based on Multiple Changes in Variation}

Conduct local optimization first and then conduct variation when the local optimum is realized to seek the next local optimum. The advantage is the higher possibility of realizing the overall optimum, and the disadvantage is the long time required for the optimization process in the early stage. The obvious variations should be addressed.

\subsection{Local Optimum and Global Optimum Model}

Adopt the overall fitness of the enterprise inner innovation to reflect its innovation evolution rule, including the MFLO (mean fitness of local optima) and MFGO (mean fitness of global optima). The former represents the mean value of all local fitness optima in the system evolution process, wherein the local fitness optima is the fitness value when the system status evolves to an approximate status without obtaining higher fitness. The latter represents the mean value of overall optimal fitness, namely, the highest fitness obtained in the whole system status process.

$$
\begin{gathered}
\text { MFLO }=\frac{1}{n \times m} \sum_{j=1}^{n} \sum_{m=0}^{8} \max _{m}\left(\omega_{m}(x)\right) \\
M F G O=\frac{1}{n \times m} \sum_{j=1}^{n} \sum_{m=0}^{8} \max _{m}\left(W_{m}\right)
\end{gathered}
$$

where $\mathrm{NS}_{\mathrm{m}}$ represents the 8 types of interaction situations in the enterprise inner innovation system, $\mathrm{x} \in \mathrm{NS}_{\mathrm{m}}, \mathrm{m}=0,1, \ldots, 7, \mathrm{~W}_{\mathrm{j}}$ represents the fitness of the $\mathrm{j}$ situation, and the simulation times $\mathrm{n}=500$.

\section{Results}

In this simulation, the inner innovation dimension $\mathrm{N}=22$, and complexity $0 \leq \mathrm{K} \leq 7$ aligns with previous studies $[56,60,61]$. At the same time, to analyze the effect of the inner innovation of large-scale enterprises under a context of weak relationships, strong relationships and super-strong relationships between dimensions, the relationship intensities $\lambda$ between dimensions (out) are 0.3 , 0.5 and 0.7 , respectively, and the relationship intensities $\lambda$ between dimensions (in) are $0.2,0.5$ and 0.8 , respectively. The $\lambda$ matrix has 9 situations in total.

\subsection{Fitness Landscape Map}

To obtain the fitness function of the LSCE inner innovation system, the Formula (1) was used to obtain the fitness landscape under different $K$ values (the range of $K$ is $0-6$ ) and different $N$ values (the range of $\mathrm{N}$ is 6-22), as shown in the following Figure 1.

Different $\mathrm{N}$ and $\mathrm{K}$ values will generate different fitness landscapes with different roughness degrees, and the key concept reflecting the fitness landscape roughness is the optimal number of vertex (overall optimal point) and the local optimal point. With an increase in the K value, the relationship range of internal factors in the inner innovation system will be larger, the number of factors with interactions will increase and the fitness landscape will present the feature of high roughness. 


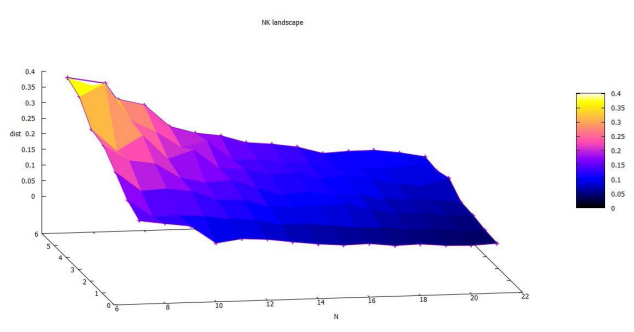

$\lambda($ in $)=0.2, \lambda($ out $)=0.3$

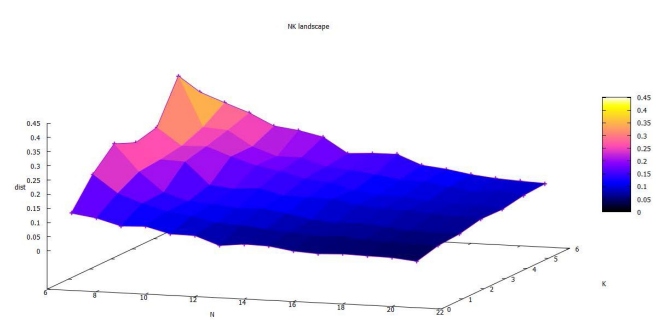

$\lambda($ in $)=0.5, \lambda($ out $)=0.3$

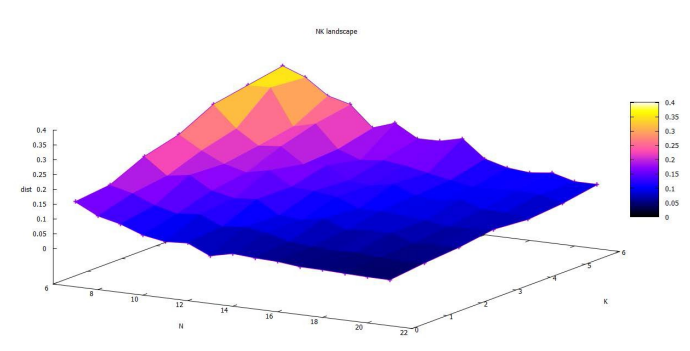

$\lambda($ in $)=0.8, \lambda($ out $)=0.3$

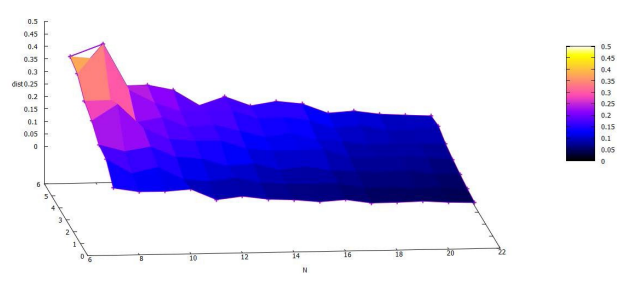

$\lambda($ in $)=0.2, \lambda($ out $)=0.5$

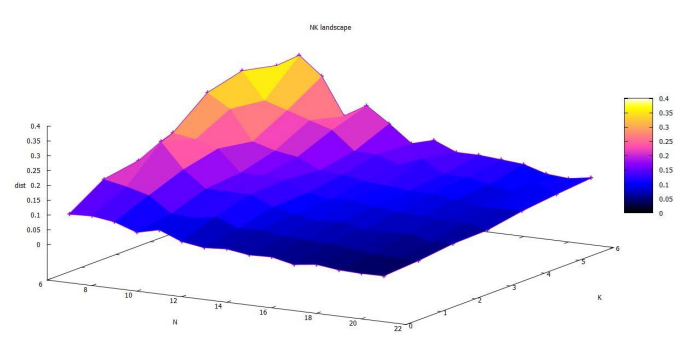

$\lambda($ in $)=0.5, \lambda($ out $)=0.5$

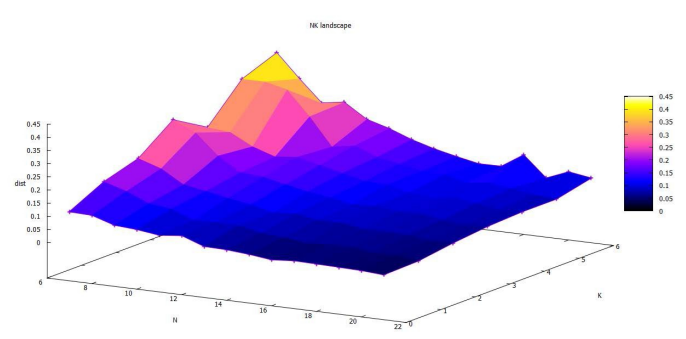

$\lambda($ in $)=0.8, \lambda($ out $)=0.5$

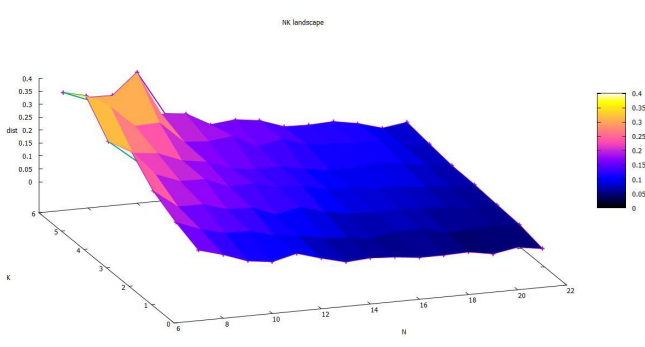

$\lambda($ in $)=0.2, \lambda($ out $)=0.7$

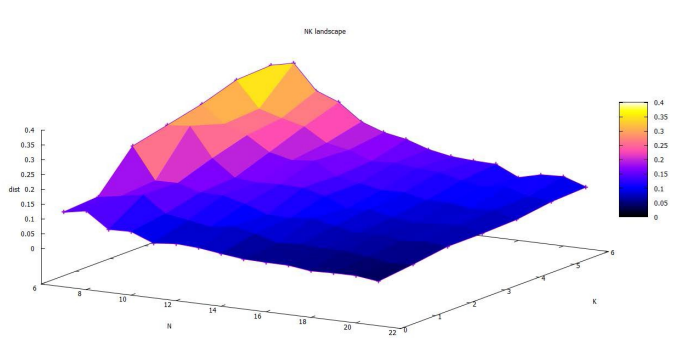

$\lambda($ in $)=0.5, \lambda($ out $)=0.7$

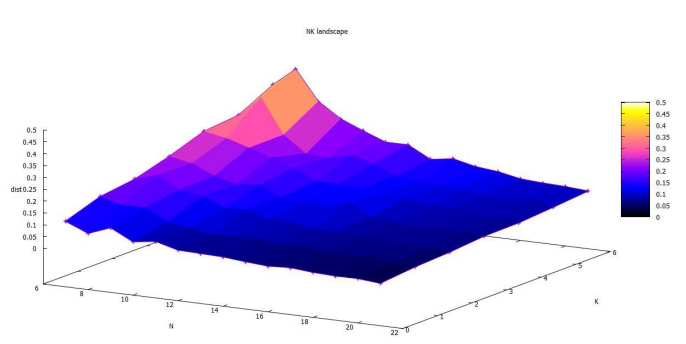

$\lambda($ in $)=0.8, \lambda($ out $)=0.7$

Figure 1. Fitness landscape map. Note: in the fitness landscape map, the degree of ruggedness between peak and valley is described by colors of different depths. The blue darker color in the horizontal axis, the flatter it is. i.e., There are no many local best points. The brighter the longitudinal axial color, indicating that the mountain is more rugged and there are many "peaks", i.e., There are many local best points. 
With $\mathrm{K}-6$, the number of factors reaches the maximum value, and the fitness landscape reaches the highest point. In addition, when the relationship intensity $\lambda$ is 0.5 and 0.8 , while the relationship intensity $\lambda$ is 0.2 and 0.3 , the fitness landscape maps are at the highest values when $K=6$ and $N=6$. This which shows that the fitness landscape reaches its vertex when the number of internal factors of the inner innovation system is equal to the number of relations between factors.

Furthermore, based on the analysis of the 9 fitness landscape maps, set the K value randomly, and regardless of how the relationship intensity changes, the fitness landscape will decrease with the increase in $\mathrm{N}$. Set the $\mathrm{N}$ value randomly, and regardless of how the relationship intensity changes, the fitness landscape will increase with the increase in $\mathrm{K}$. This shows that the relationship intensity has little influence on the fitness landscape. The vertex of the fitness landscape mainly depends on $\mathrm{K}$ and $\mathrm{N}$. When $\mathrm{K}$ approaches $\mathrm{N}$, the number of relations between internal factors in the inner innovation system increases, and the performance of the inner innovation becomes higher.

\subsection{Individual Fitness}

Following the classic NK model in Section 3.1, individual fitness under different relationship intensities is shown in Figure 2.

Based on a comparative analysis of individual fitness, the fitness landscape maps reveal the following. Regardless of how relationship intensity changes, the fitness value increases with the increase in K. In addition, the individual fitness changes little under different relationship intensities. 


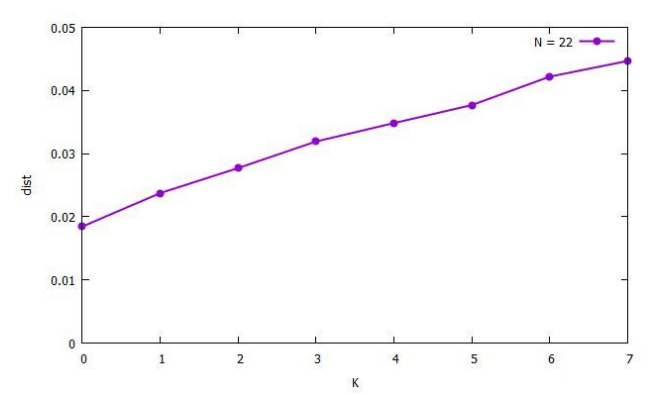

$\lambda($ in $)=0.2 \lambda($ out $)=0.3$

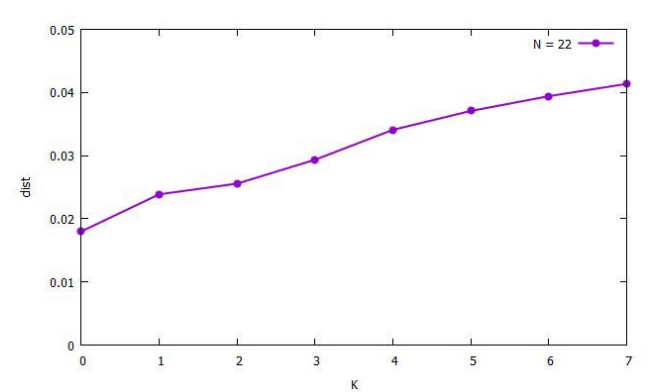

$\lambda($ in $)=0.5 \lambda($ out $)=0.3$

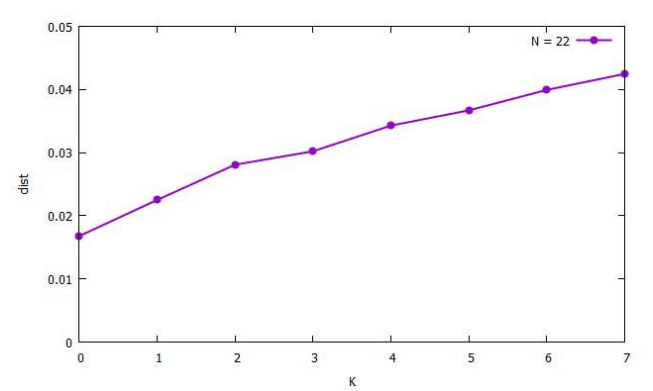

$\lambda($ in $)=0.8 \lambda($ out $)=0.3$

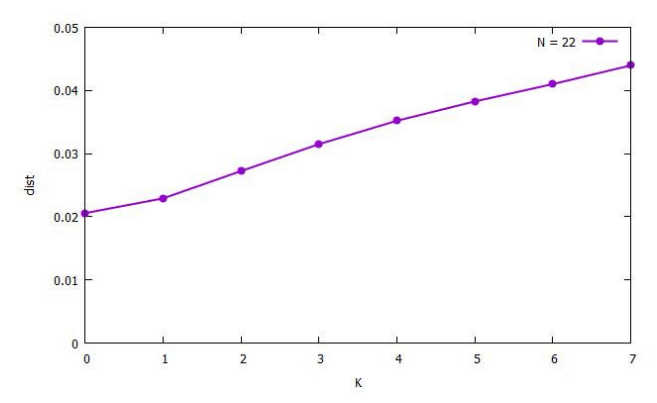

$\lambda($ in $)=0.2 \lambda($ out $)=0.5$

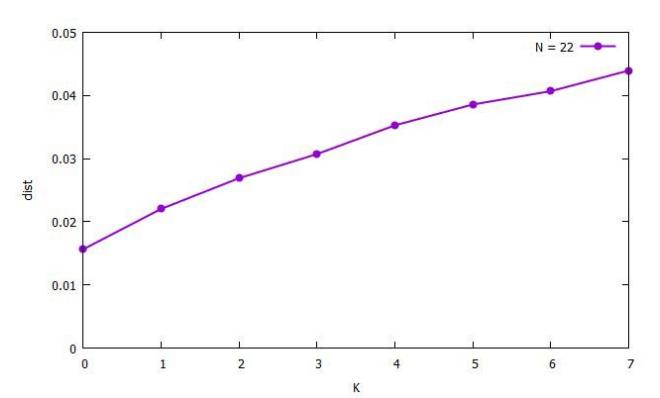

$\lambda($ in $)=0.5 \lambda($ out $)=0.5$

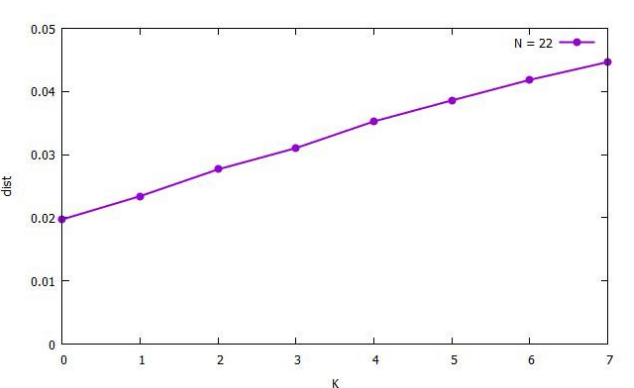

$\lambda($ in $)=0.8 \lambda($ out $)=0.5$

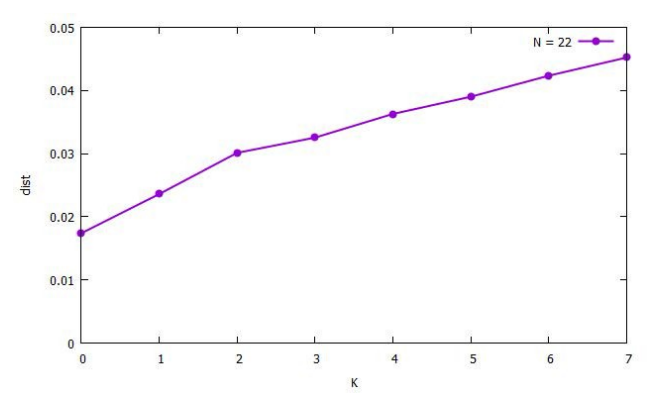

$\lambda($ in $)=0.2 \lambda($ out $)=0.7$

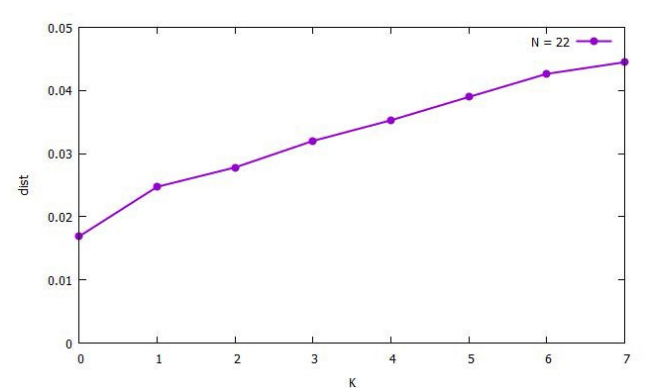

$\lambda($ in $)=0.5 \lambda($ out $)=0.7$

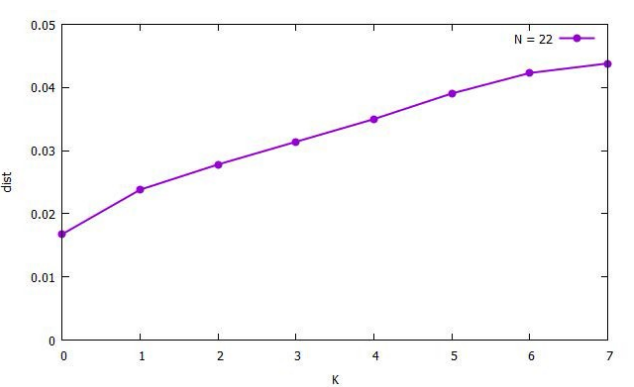

$\lambda($ in $)=0.8 \lambda($ out $)=0.7$

Figure 2. Individual fitness under different relationship intensities. Note: $K=7, \mathrm{~N}=22$ and these graphs related to the graphs in Figure 1. 


\subsection{Comparison of Ambidexterity, Punctuated Equilibrium and Automation}

The analysis of the fitness landscape and individual fitness reveals that the larger the $\mathrm{K}$ is, the higher the inner innovation performance. Furthermore, following Table 2 (sets $K=7$ ) a comparative analysis of ambidexterity, punctuated equilibrium and automation under different relation intensities was conducted. The probability of the inner innovation in the NK model is $\mathrm{R}=0.5$, and $\varepsilon=3 / 10, \mathrm{t}=10$ in the punctuated equilibrium mode. Thereafter, following the calculation method in Section 3.2, the LSCE inner innovation system performance curve under different relationship intensities is shown in Figure 3.

As shown in Table 3, regardless of the optimization mode (either ambidexterity or punctuated equilibrium or automation) the enterprise adopts, the inner innovation will increase over time. Under the same relationship intensity, different modes will deliver different performances. From a short-term perspective, performance changes largely without obvious rules, while from a long-term perspective, punctuated equilibrium delivers the highest performance, automation delivers the lowest, and ambidexterity offers moderate performance.

Table 3. Key node of different relationship intensities in the optimization process.

\begin{tabular}{|c|c|c|c|c|c|c|c|}
\hline & & $\mathrm{T}=50$ & $\mathrm{~T}=100$ & $\mathrm{~T}=200$ & $\mathrm{~T}=300$ & $\mathrm{~T}=400$ & $\mathrm{~T}=500$ \\
\hline \multirow{3}{*}{$\begin{array}{c}\lambda(\text { in })=0.2 \\
\lambda(\text { out })=0.3\end{array}$} & A & 2.76077 & 2.97323 & 3.32073 & 3.32073 & 3.32073 & 3.32073 \\
\hline & B & 3.58051 & 3.58051 & 3.58051 & 3.58051 & 3.58051 & 3.58051 \\
\hline & $\mathrm{C}$ & 2.11247 & 2.37101 & 2.61232 & 2.61232 & 2.61232 & 2.70414 \\
\hline \multirow{3}{*}{$\begin{array}{c}\lambda(\text { in })=0.2 \\
\lambda(\text { out })=0.5\end{array}$} & A & 2.21903 & 2.64604 & 3.08783 & 3.08783 & 3.08783 & 3.08783 \\
\hline & B & 2.17567 & 2.94663 & 3.16921 & 3.16921 & 3.16921 & 3.16921 \\
\hline & C & 1.77164 & 2.88827 & 2.88827 & 2.88827 & 2.88827 & 2.88827 \\
\hline \multirow{3}{*}{$\begin{array}{c}\lambda(\text { in })=0.2 \\
\lambda(\text { out })=0.7\end{array}$} & A & 2.56552 & 3.11355 & 3.11355 & 3.2068 & 3.2068 & 3.2068 \\
\hline & B & 2.63468 & 2.71202 & 2.71202 & 2.71202 & 2.71202 & 2.71202 \\
\hline & $\mathrm{C}$ & 1.8737 & 1.8737 & 1.8737 & 1.8737 & 1.96299 & 2.15957 \\
\hline \multirow{3}{*}{$\begin{array}{c}\lambda(\text { in })=0.5 \\
\lambda(\text { out })=0.3\end{array}$} & A & 2.23308 & 2.23308 & 2.23308 & 2.23308 & 2.23308 & 2.28873 \\
\hline & B & 2.38477 & 2.51369 & 2.55449 & 2.84755 & 2.84755 & 3.67153 \\
\hline & $\mathrm{C}$ & 1.57837 & 1.75192 & 1.76204 & 2.43567 & 2.7466 & 2.7466 \\
\hline \multirow{3}{*}{$\begin{array}{c}\lambda(\text { in })=0.5 \\
\lambda(\text { out })=0.5\end{array}$} & A & 2.5154 & 2.70884 & 2.70884 & 2.70884 & 2.70884 & 2.78674 \\
\hline & B & 2.70391 & 2.70391 & 2.70391 & 2.70391 & 2.70391 & 2.70391 \\
\hline & $\mathrm{C}$ & 1.73552 & 1.84098 & 2.26965 & 2.35567 & 2.35567 & 2.35567 \\
\hline \multirow{3}{*}{$\begin{array}{c}\lambda(\text { in })=0.5 \\
\lambda(\text { out })=0.7\end{array}$} & A & 2.024 & 2.74477 & 2.77296 & 2.85153 & 2.85153 & 2.85153 \\
\hline & B & 2.66431 & 2.66431 & 2.67121 & 2.89385 & 2.89385 & 2.89385 \\
\hline & $\mathrm{C}$ & 1.95911 & 1.95911 & 1.992 & 1.992 & 2.22676 & 2.67608 \\
\hline \multirow{3}{*}{$\begin{array}{c}\lambda(\text { in })=0.8 \\
\lambda(\text { out })=0.3\end{array}$} & A & 2.18344 & 2.18344 & 2.30263 & 2.82931 & 2.82931 & 2.82931 \\
\hline & B & 3.27182 & 3.5054 & 3.82783 & 3.82783 & 3.82783 & 3.82783 \\
\hline & $\mathrm{C}$ & 1.4442 & 1.4442 & 2.16122 & 2.16122 & 2.16122 & 2.20016 \\
\hline \multirow{3}{*}{$\begin{array}{c}\lambda(\text { in })=0.8 \\
\lambda(\text { out })=0.5\end{array}$} & A & 1.77104 & 1.77104 & 2.66919 & 3.07717 & 3.07717 & 3.07717 \\
\hline & B & 2.53127 & 2.92678 & 3.31014 & 3.31302 & 3.31302 & 3.31302 \\
\hline & $\mathrm{C}$ & 1.99093 & 2.18899 & 2.18899 & 2.21769 & 2.21769 & 2.21769 \\
\hline \multirow{3}{*}{$\begin{array}{c}\lambda(\text { in })=0.8 \\
\lambda(\text { out })=0.7\end{array}$} & A & 2.39417 & 2.63752 & 2.75129 & 2.82009 & 2.82009 & 2.82009 \\
\hline & B & 3.01634 & 3.01634 & 3.24621 & 3.24621 & 3.24621 & 3.24621 \\
\hline & $\mathrm{C}$ & 1.78319 & 2.02588 & 2.18755 & 2.51981 & 2.7775 & 2.7775 \\
\hline
\end{tabular}

Note: $\mathrm{A}=$ Ambidexterity; $\mathrm{B}=$ Punctuated equilibrium; $\mathrm{C}=$ Automation. Additionally, we use the $\lambda($ in $)=0.5$, then $\lambda$ (out) $=$ from $0.3,0.5$ to 0.7 , and we can compare the result. 


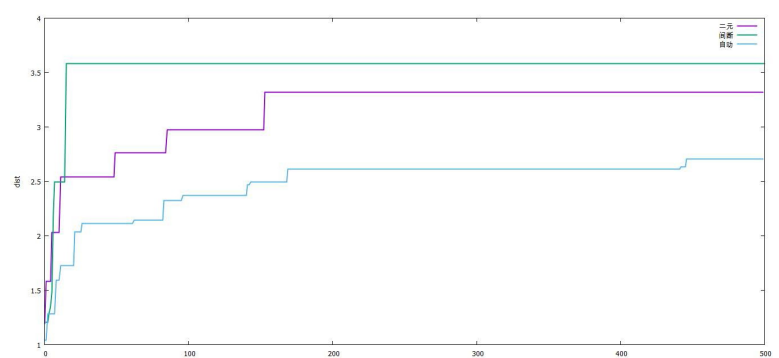

$\lambda($ in $)=0.2 \lambda($ out $)=0.3$

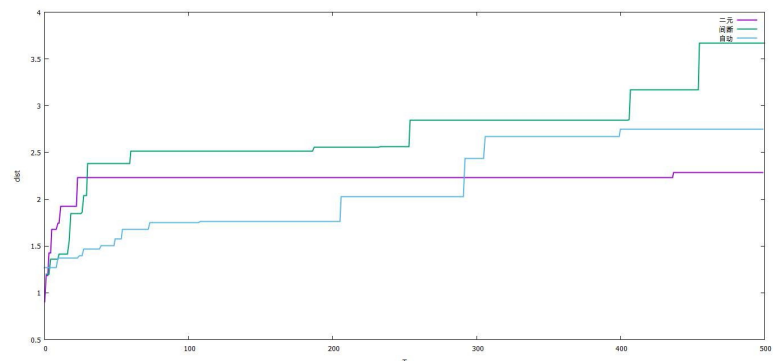

$\lambda($ in $)=0.5 \lambda($ out $)=0.3$

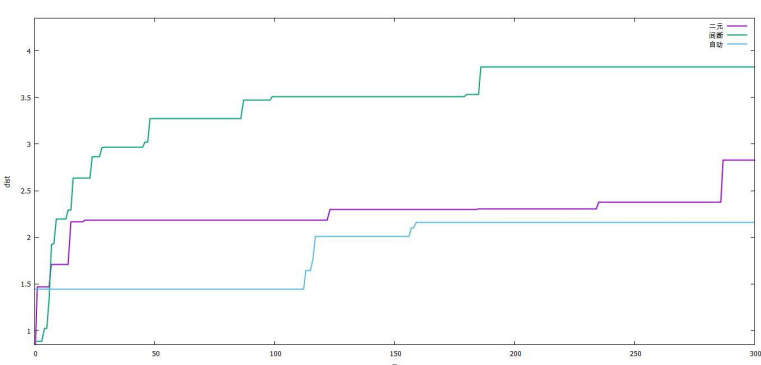

$\lambda(\mathrm{in})=0.8 \lambda(\mathrm{out})=0.3$

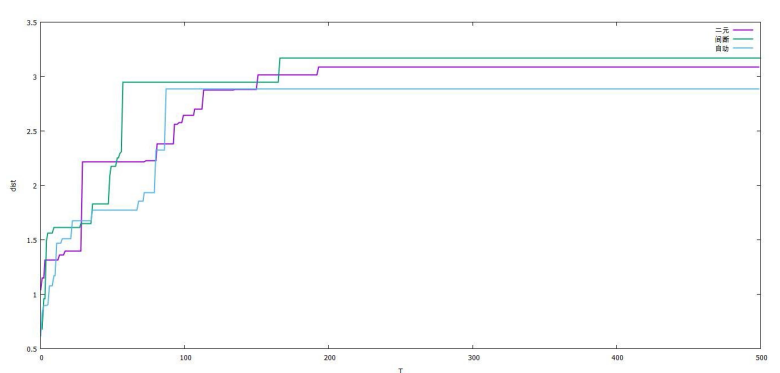

$\lambda(\mathrm{in})=0.2 \lambda(\mathrm{out})=0.5$

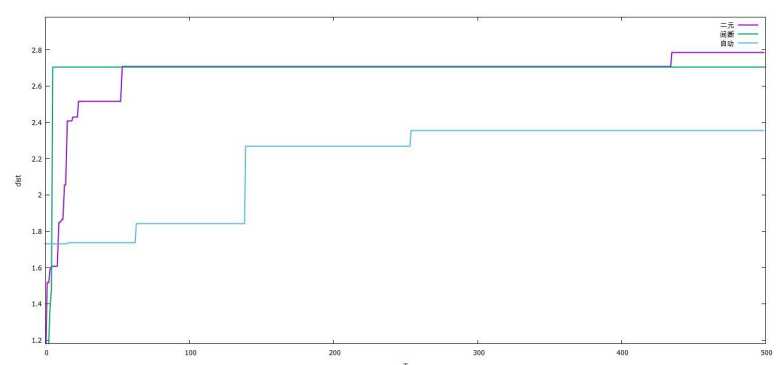

$\lambda($ in $)=0.5 \lambda($ out $)=0.5$

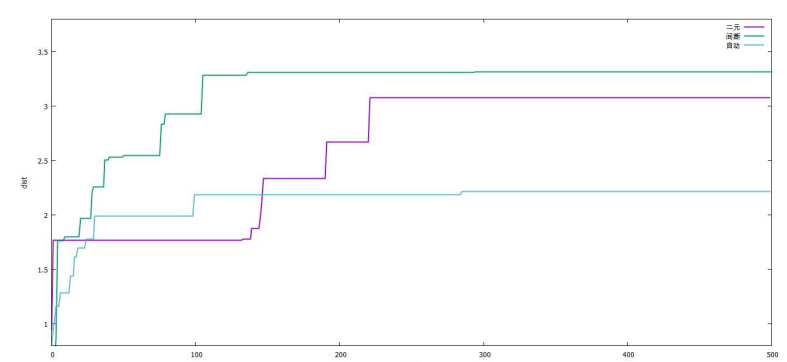

$\lambda($ in $)=0.8 \lambda($ out $)=0.5$

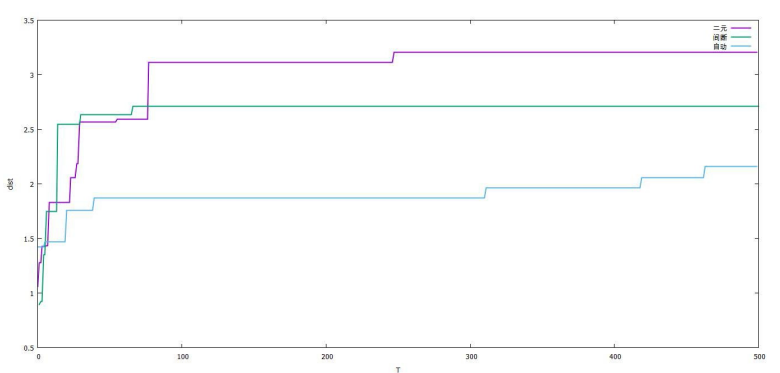

$\lambda($ in $)=0.2 \lambda($ out $)=0.7$

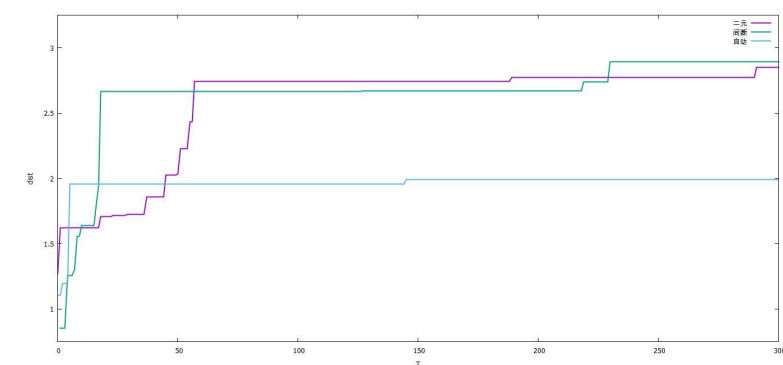

$\lambda($ in $)=0.5 \lambda($ out $)=0.7$

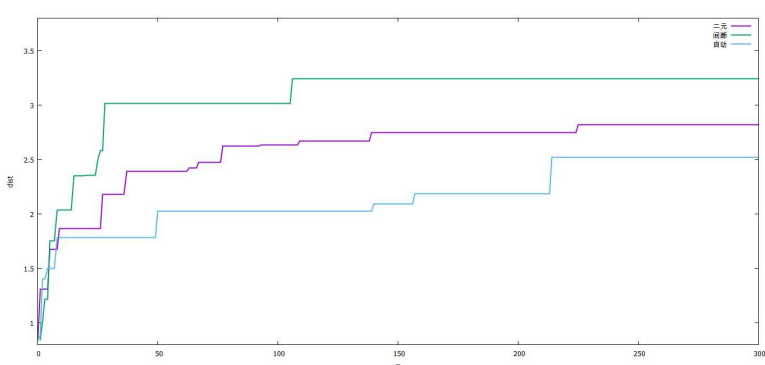

$\lambda($ in $)=0.8 \lambda($ out $)=0.7$

Figure 3. LSCE control force performance curve under different relationship intensities. Note: $K=7, N=22$ 
When the inter-dimensional relationship intensity is 0.2 and the relationship intensity between dimensions is 0.7 , namely, when the former is weak while the latter is super-strong, the highest performance of ambidexterity is 3.2068 and the lowest performance of automation is 2.71202. In this context, the punctuated equilibrium is modest, at 0.49478 for the performance of ambidexterity. When the difference is larger, the situation should be analyzed singly. When the inter-dimensional relationship intensity and the relationship intensity between dimensions are both 0.5 (strong relationship), the highest performance of ambidexterity is 2.78674 and the lowest performance of automation is 2.35567; here, the punctuated equilibrium is modest, 0.08283 the performance of ambidexterity. 0.08283 from that of ambidexterity.

From a short-term perspective, the situations from the starting point to $\mathrm{T}=50$ and $\mathrm{T}=100$ are mainly analyzed. When the inter-dimensional relationship intensity is 0.2 (weak relationship), generally, the punctuated equilibrium will increase inner innovation performance largely within a short time. When the inter-dimensional relationship intensity is 0.5 and the relationship intensity between dimensions is strong or super-strong, the punctuated equilibrium should be selected to enhance the inner innovation rapidly from the perspective of short-term performance.

\subsection{Local Optimal and Overall Optimal Analysis}

Based on Formulas (7) and (8), the local optimal fitness mean value (L) and overall optimal fitness mean value were obtained under all situations and the results shown in Table 4.

Table 4. Overall inner innovation fitness under different relationship numbers and intensities.

\begin{tabular}{|c|c|c|c|c|c|c|c|c|c|}
\hline & & $\mathbf{k}=\mathbf{0}$ & $k=1$ & $\mathbf{k}=2$ & $\mathbf{k}=3$ & $k=4$ & $k=5$ & $k=6$ & $k=7$ \\
\hline \multirow{2}{*}{$\begin{array}{c}\lambda(\text { in })=0.2 \\
\lambda(\text { out })=0.3\end{array}$} & G & 0.0358 & 0.056 & 0.0507 & 0.0691 & 0.0784 & 0.0834 & 0.103 & 0.1291 \\
\hline & $\mathrm{L}$ & 0.0358 & 0.0507 & 0.0486 & 0.064 & 0.0761 & 0.0813 & 0.094 & 0.1217 \\
\hline \multirow{2}{*}{$\begin{array}{c}\lambda(\text { in })=0.2 \\
\lambda(\text { out })=0.5\end{array}$} & G & 0.0346 & 0.0387 & 0.0682 & 0.0759 & 0.0853 & 0.1101 & 0.094 & 0.1253 \\
\hline & $\mathrm{L}$ & 0.0342 & 0.0364 & 0.0541 & 0.0627 & 0.0748 & 0.0914 & 0.092 & 0.1105 \\
\hline \multirow{2}{*}{$\begin{array}{c}\lambda(\text { in })=0.2 \\
\lambda(\text { out })=0.7\end{array}$} & G & 0.0378 & 0.0509 & 0.0587 & 0.0639 & 0.0851 & 0.0984 & 0.095 & 0.1324 \\
\hline & $\mathrm{L}$ & 0.0321 & 0.049 & 0.0562 & 0.0578 & 0.0753 & 0.0948 & 0.093 & 0.1159 \\
\hline \multirow{2}{*}{$\begin{array}{c}\lambda(\text { in })=0.5 \\
\lambda(\text { out })=0.3\end{array}$} & G & 0.0295 & 0.046 & 0.0567 & 0.0597 & 0.0815 & 0.0993 & 0.092 & 0.1039 \\
\hline & $\mathrm{L}$ & 0.0291 & 0.0442 & 0.052 & 0.0543 & 0.0781 & 0.0944 & 0.086 & 0.1008 \\
\hline \multirow{2}{*}{$\begin{array}{c}\lambda(\text { in })=0.5 \\
\lambda(\text { out })=0.5\end{array}$} & G & 0.0352 & 0.0453 & 0.0655 & 0.0767 & 0.0832 & 0.0971 & 0.11 & 0.1593 \\
\hline & $\mathrm{L}$ & 0.0338 & 0.0445 & 0.0604 & 0.0728 & 0.081 & 0.0824 & 0.096 & 0.1425 \\
\hline \multirow{2}{*}{$\begin{array}{c}\lambda(\text { in })=0.5 \\
\lambda(\text { out })=0.7\end{array}$} & G & 0.0275 & 0.0506 & 0.0572 & 0.0608 & 0.0839 & 0.0947 & 0.13 & 0.1573 \\
\hline & $\mathrm{L}$ & 0.0269 & 0.0486 & 0.0544 & 0.0586 & 0.081 & 0.0835 & 0.121 & 0.1506 \\
\hline \multirow{2}{*}{$\begin{array}{c}\lambda(\text { in })=0.8 \\
\lambda(\text { out })=0.3\end{array}$} & G & 0.0348 & 0.0364 & 0.0595 & 0.058 & 0.0786 & 0.1128 & 0.117 & 0.1405 \\
\hline & $\mathrm{L}$ & 0.0285 & 0.0356 & 0.0549 & 0.0543 & 0.0646 & 0.0874 & 0.104 & 0.1266 \\
\hline \multirow{2}{*}{$\begin{array}{c}\lambda(\text { in })=0.8 \\
\lambda(\text { out })=0.5\end{array}$} & G & 0.0348 & 0.0496 & 0.0573 & 0.0721 & 0.0775 & 0.0996 & 0.105 & 0.1456 \\
\hline & $\mathrm{L}$ & 0.0339 & 0.0477 & 0.0571 & 0.0606 & 0.0743 & 0.0885 & 0.083 & 0.1259 \\
\hline \multirow{2}{*}{$\begin{array}{c}\lambda(\text { in })=0.8 \\
\lambda(\text { out })=0.7\end{array}$} & G & 0.0309 & 0.0431 & 0.0567 & 0.0679 & 0.0858 & 0.0838 & 0.102 & 0.1366 \\
\hline & $\mathrm{L}$ & 0.0301 & 0.0416 & 0.0509 & 0.0649 & 0.0722 & 0.0801 & 0.09 & 0.1225 \\
\hline
\end{tabular}

Note: $\mathrm{L}=$ local, $\mathrm{G}=$ global. The global curve is the mean value curve of overall optimal fitness, and the local curve is the mean value curve of local optimal fitness, as shown in the following figure.

Then, following the optimization mode in Section 3.3, the curves for local optimal fitness and overall optimal fitness are shown in Figure 4. 


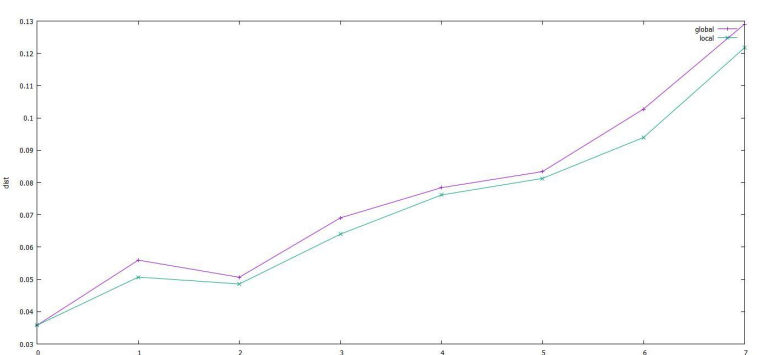

$\lambda($ in $)=0.2 \lambda($ out $)=0.3$

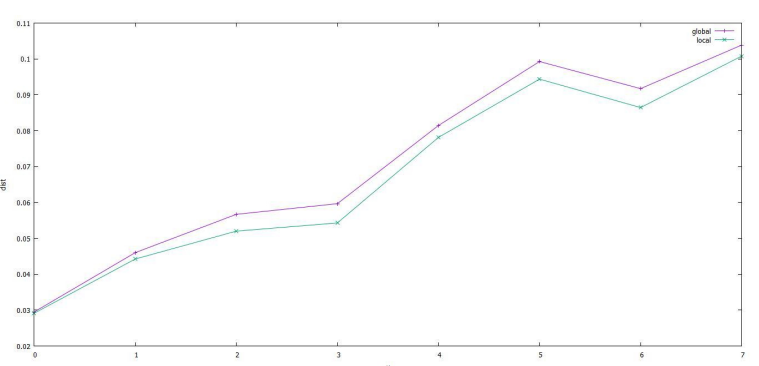

$\lambda($ in $)=0.5 \lambda($ out $)=0.3$

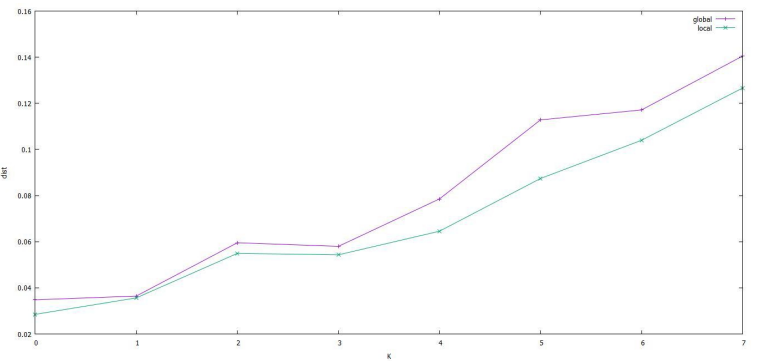

$\lambda($ in $)=0.8 \lambda($ out $)=0.3$

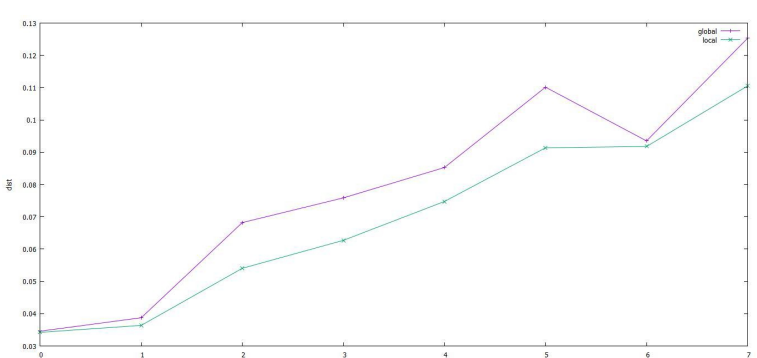

$\lambda($ in $)=0.2 \lambda($ out $)=0.5$

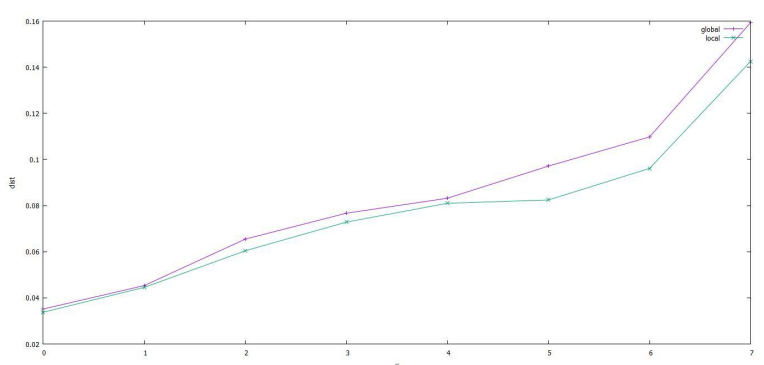

$\lambda($ in $)=0.5 \lambda($ out $)=0.5$

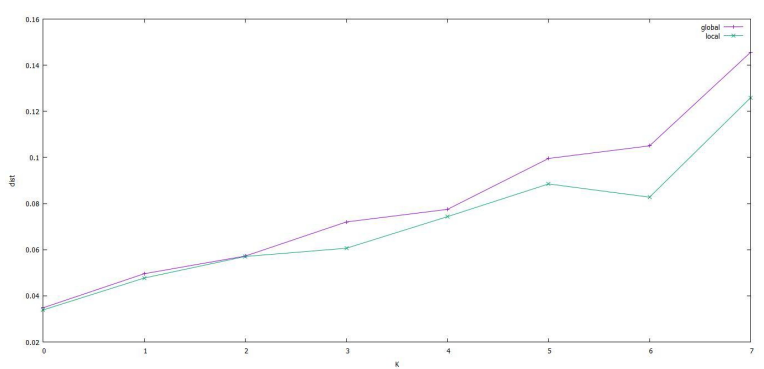

$\lambda($ in $)=0.8 \lambda($ out $)=0.5$

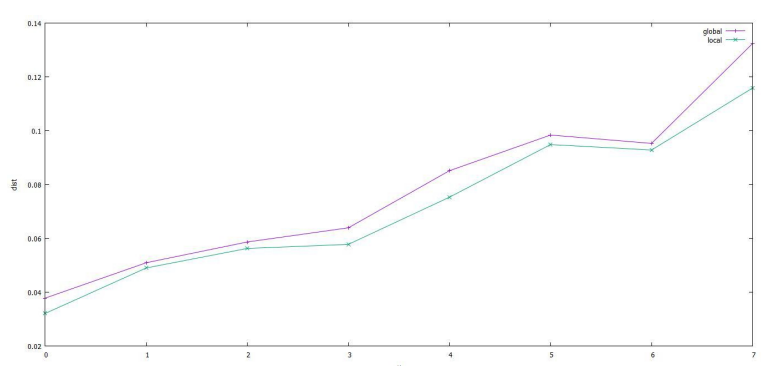

$\lambda($ in $)=0.2 \lambda($ out $)=0.7$

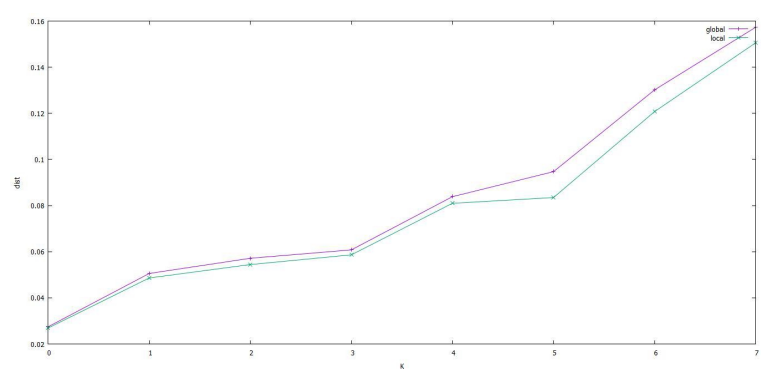

$\lambda($ in $)=0.5 \lambda($ out $)=0.7$

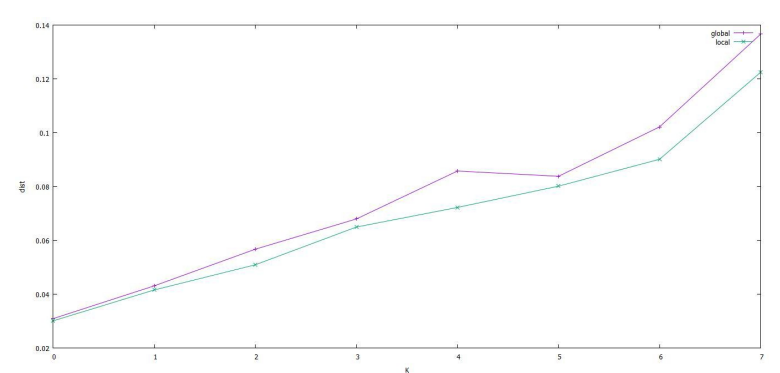

$\lambda($ in $)=0.8 \lambda($ out $)=0.7$

Figure 4. Curves of local optimal fitness and overall optimal fitness. Note: $K=7, \mathrm{~N}=22$. 
It can be seen in Figure 4 that regardless of how the inter-dimensional relationship intensity and relationship intensity between dimensions of the LSCE inner innovation system change, the local optimal fitness mean value and overall optimal fitness mean value will increase with an increase in the number of relation factors. This suggests that the more complex and closer the relationship is between internal factors of the LSCE inner innovation system, the higher the fitness mean value is. The enterprises with more relation factors will not only intensify the overall enterprise benefit and strengthen the mutual coordination role between factors, which is far greater than the performance formed between inner innovation factors, but also enhance the competitiveness and stability of the enterprise to provide an incomparable competitive advantage over other enterprises.

\section{Discussion}

Long-term competitiveness in enterprises can be sustained only by balancing both the applied and exploratory reforms $[62,63]$. Applied reform refers to the micro-changes based on the existing structure and knowledge to satisfy the current development of the enterprise and guarantee enterprise competitiveness through short-term development [64]. Exploratory reform refers to major adjustments in range and degree based on new knowledge to guarantee enterprise competitiveness through long-term development [65]. Companies such as Kodak are no longer competitive and have dropped out of business due to the imbalance between applied and exploratory reform. Similar to previous studies, this study has developed a NK model of the enterprise inner innovation system in LSCE. For instance, Jian et al. [66] adopted the modes of ambidexterity and punctuated equilibrium to simulate the influence of alliance network structure on the selection of enterprise innovation balance based on the NK model, the fitness landscape theory and complex network theory simulation. Similarly, Bo et al. [67] establishes the NK model from the perspective of enterprise cluster innovation capability and explores the enterprise cluster innovation capability development route under different cluster features. The difference in this study is that the NK model of enterprise innovation in LSCE is applicable in the construction industry context. Therefore, it contributes to the body of knowledge by providing insights for enhancing innovation in the construction industry.

The change in the inner innovation system has two types of methods: one is a local adjustment to adapt to industrial change and satisfy the development demands of enterprise [68] and the other conducts intense organizational reform or reforms behavior to pursue higher performance and satisfy the future development of the enterprise [69]. In the developed NK model of enterprise inner innovation in LSCE, a change in the inner innovation results to change in one of the factors of the inner innovation system and form a new vector to obtain new performance in the fitness landscape. When the LSCE vary the inner innovation, each type of factor will change with a certain probability. The enterprise will determine whether to retain a new vector and performance through a comparison with the original performance [70]. If the performance of the new vector in the fitness landscape increases, it will retain the new vector and performance; otherwise, it will retain the original system.

From the perspective of long-term development, the LSCE should select the punctuated equilibrium to enhance inner innovation performance, namely, in one circulation, the LSCE have a large scale with many factors influencing the inner innovation. While enterprise resources are limited, the exploratory and applied reform of the inner innovation are difficult to implement simultaneously; therefore, the ambidextrous mode has no absolute advantage [71]. The applied reform of the inner innovation changes little in the original inner innovation system; therefore, it has a high success rate and rapidly enhances performance. Exploratory reform can avoid the dilemma of being trapped at a local summit through a leap-type movement and can thus obtain a higher performance level, but it requires many external resources and changes, largely with a low success rate and slow performance growth. Because the punctuated equilibrium has a greater proportion in applied reform than ambidexterity, it is easier to obtain higher performance within the short term, and in the long run, it can enhance LSCE inner innovation performance. When the inter-dimensional relationship is weak while the relationship between dimensions is too strong or when the inter-dimensional relationship 
and relationship between dimensions are both strong, the ambidextrous mode should be adopted to obtain higher inner innovation performance to conduct broad reform in the organization, break through the short-term balance of the inner innovation and obtain higher performance.

\section{Conclusions}

This paper establishes the NK model of enterprise inner innovation in LSCE. It introduces relationship intensity into the inner innovation environment when describing $\mathrm{K}$, discusses the different combinations of the inter-dimensional relationship and the relationship between dimensions within the inner innovation system, and adopts the three methods of ambidexterity, punctuated equilibrium, and automation to simulate the change behavior of the inner innovation system. It not only analyses the differences in the optimization method but also provides the optimal optimization method under different environments. In addition, this research regulates the K value (namely, the complexity of fitness geography) to calculate individual and optimal fitness and analyses the influence of the factor relation on inner innovation performance. Theoretically, this study provides a beneficial analogue simulation reference for how LSCE can realize the optimal status of the inner innovation and provides new ideas for LSCE inner innovation enhancement under a specific environment.

The fitness landscape of the NK model of enterprise innovation in LSCE reaches its vertex when the number of internal factors of the inner innovation system is equal to the number of relations between factors. In addition, the relationship intensity has little influence on the fitness landscape. Meanwhile, the fitness value increases with the increase in the value of $\mathrm{K}$ regardless of how relationship intensity changes. Thus, the larger the $\mathrm{K}$ is, the higher the innovation performance in LSCE. The inner innovation in LSCE increases over time under the ambidexterity, punctuated equilibrium, and automation modes of optimization. However, the different modes optimization deliver different performances under the same relationship intensity. In the short term, performance changes largely without obvious rules. In the long term, the punctuated equilibrium, ambidexterity, and automation produce the best performance, moderate and least performances, respectively. Finally, regardless of how the inter-dimensional intensity and relationship intensity in the LSCE inner innovation system change, the local and the overall optimal fitness mean values increase with an increase in the number of relational factors. Therefore, the LSCE with more relational factors will be more competitive. In conclusion, many interactive factors are responsible for the inner innovation in the LSCE, while the forms of changing behavior of the inner innovation in the LSCE are ambidexterity, punctuated equilibrium, and automation.

Practically, the simulated NK model of enterprise innovation provides a reflection of how inner innovation in LSCE in the construction industry can be managed. Only one factor of inner innovation may be inadequate in LSCE in the construction industry. Instead, many factors of inner innovation are necessary. In addition, the interaction between the factors need to be considered to improve innovation performance in LSCE. The limitation of this study is as follows. Enterprises in the construction industry could either be large or small, and innovation in either of them could be distinct due to resources availability. The large enterprises tend to have more resources to commit to innovation. Meanwhile, the NK model of enterprise innovation is applicable in large enterprises, and therefore inapplicable in small enterprises. Future studies should fill this gap. In future, NK models for enterprise innovation should give cognizance to the different sizes of enterprises in the construction industry.

Author Contributions: Conceptualization, T.C. and G.H.; Methodology, T.C.; Software, T.C. and G.H.; Validation, T.C., G.H. and A.O.O.; Formal Analysis, T.C.; Data Curation, T.C.; Writing-Original Draft Preparation, T.C.; Writing-Review \& Editing, T.C., G.H. and A.O.O.; Supervision, T.C. and G.H.

Funding: This research was funded by the National Natural Science Foundation of China [No. 71301013]; Humanty and Social Science Program Foundation of the Ministry of Education of China [No. 17YJA790091]; Shaanxi Social Science Fund [No. 2017S004, No. 2017Z028, No. 2016ZB017, No. $2016 Z 047$ and No. 2014HQ10]; Xi'an Social Science Fund [No. 18J139]; Xi'an Construction Science and Technology Planning Project [No. SJW201705]; Xi'an Science Technology Bureau Fund (No. 201805070RK1SF4(6)); Shaanxi Universities Second Batch of Youth Outstanding Talents Support Projects [[2018]111]; Shaanxi Province Higher Education Teaching Reform Project 
[No. 17BZ017]; Education Funding of Master of Engineering Management in China [No. 2017-ZX-004]; Shaanxi Province Civil Engineering "first-class professional" project [No. 300103282803 and No. 0012-310628170124]; Special Fund for Graduate Student Education Reform of Central College, Chang'an University [No.300111002005, No.300103187091 and No.310628161406]; Fundamental Research for Education Reform of Central College, Chang'an University [No. 300104282301, No. 300104282318, No. 300104282323, No. 310623172904, No. 310623171003 and No. 310623171633]; Fundamental Research for Funds for the Central Universities (Humanities and Social Sciences), Chang'an University [No. 300102418659]; Fundamental Research for Funds for the Central Universities, Chang'an University [No. 300102238201].

Acknowledgments: The authors gratefully acknowledge valuable suggestions by the expert panel, and give special thanks to design and construction professionals who completed the survey.

Conflicts of Interest: The authors declare no conflict of interest.

\section{References}

1. Zhang, J.; Xie, H.; Schmidt, K.; Li, H. A new systematic approach to vulnerability assessment of innovation capability of construction enterprises. Sustainability 2016, 8, 25. [CrossRef]

2. Zhang, J.X.; Li, H.; Xia, B.; Skitmore, M. Impact of environment regulation on the efficiency of regional construction industry: A 3-stage data envelopment analysis (DEA). J. Clean. Prod. 2018, 200, 770-780. [CrossRef]

3. He, Y.; Zhou, F. An empirical study on the key factors in the implementation of financial shared services for Chinese enterprise group. Account. Res. 2013, 33, 59-66.

4. Qi, S. Study on Resource Allocation of Multi-Project Management in the Construction Enterprise Groups. Ph.D. Thesis, Huazhong University of Science and Technology, Wuhan, China, 2009.

5. Li, H.; Zhang, J.X.; Wang, C.; Wang, Y.J.; Coffey, V. An evaluation of the impact of environmental regulation on the efficiency of technology innovation using the combined DEA model: A case study of Xi'an, China. Sustain. Cities Soc. 2018, 42, 355-369. [CrossRef]

6. Zhang, J.X.; Xie, H.Y.; Li, H.; Timothy, R.; Pu, S.; Deng, Q.X.; Jin, W.X. Integrated framework of growth management for identification of service innovation levels and priorities. Sustainability 2018, 10, 33. [CrossRef]

7. Ferri, L.M.; Pedrini, M. Socially and environmentally responsible purchasing: Comparing the impacts on buying firm's financial performance, competitiveness and risk. J. Clean. Prod. 2018, 174, 880-888. [CrossRef]

8. Amran, T.G.; Yose, M.J. Design logistics performance measurement model of automotive component industry for strengthening competitiveness of dealing AEC 2015. IOP Conf. Ser. Mater. Sci. Eng. 2018, 319, 012024. [CrossRef]

9. Zhang, J.X.; Li, H.; Wang, S.H.M. Analysis and potential application of the maturity of growth management in the developing construction industry of a province of china: A case study. Sustainability 2017, 9, 36. [CrossRef]

10. Zhang, J.; Schmidt, K.; Xie, H.; Li, H. A new mixed approach for modelling and assessing environmental influences to value co-creation in the construction industry. Int. J. Prod. Res. 2016, 54, 6548-6562. [CrossRef]

11. Chen, F.; Lu, W.; Cai, J.; Yang, Q. Job-housing imbalance and commuting of coastal industrial town in Liaoning province, China. IOP Conf. Ser. Earth Environ. Sci. 2017, 94, 012027. [CrossRef]

12. He, Y.; Ran, A. Analysis of state-owned enterprises incentives. In Proceedings of the 2010 International Conference on E-Business and E-Government, Guangzhou, China, 7-9 May 2010; pp. 1088-1091.

13. Corbett, C.; Gaur, V.; Simchi-Levi, D.; Taylor, T. Editorial statement-operations management. Manag. Sci. 2017, 63. [CrossRef]

14. Frenken, K. Modelling the organisation of innovative activity using the NK-model. In Proceedings of the Nelson-and-Winter Conference, Aalborg, Denmark, 12-15 June 2001; pp. 12-16.

15. Fan, I.Y.H.; Lee, R.W.B. Design of a weighted and informed NK model for intellectual capital-based innovation planning. Expert Syst. Appl. 2012, 39, 9222-9229. [CrossRef]

16. Chesbrough, H. Managing open innovation. Res. Technol. Manag. 2004, 47, 23-26. [CrossRef]

17. Dahlander, L.; Gann, D.M. How open is innovation? Res. Policy 2010, 39, 699-709. [CrossRef]

18. West, J.; Gallagher, S. Challenges of open innovation: The paradox of firm investment in open-source software. $R$ D Manag. 2010, 36, 319-331. [CrossRef] 
19. Castro, R.R.; Clayton, R.; Hauksson, E.; Stock, J. Observations of remotely triggered seismicity in Salton sea and Coso geothermal regions, southern California, USA, after big ( $\mathrm{mw}>7.8)$ teleseismic earthquakes. Geofis. Int. 2017, 56, 269-286.

20. Choi, H.-M. The managerial spirits and company cultures of the Cadbury Brothers Ltd., as a model of social enterprise and a case study of personal capitalism. Daegusahak 2015, 120, 381-421.

21. Xia, G.; Wei, Z. Analysis of the status quo of foreign internal control research. Mod. Bus. Trade Ind. 2009, 21, 202-203.

22. Guidance to enterprise internal control evaluation. Intern. Audit. China 2010, 13, 74-75.

23. ASC. Guidance to enterprise internal control audit. Metall. Financ. Account. 2012, 31, 46-48.

24. Chen, H.F. Internal control quality evaluation looks miserable-Based on the comparison of DIBO and Xiamen university index. Financ. Account. Mon. 2014, 34, 102-105.

25. Liu, L.F.; Yao, R.H. Analysis and redesign of internal control index. Account. Financ. 2013, 27, 40-45.

26. Shao, Y.; Chen, S.; Cheng, B. Analyses of the dynamic factors of cluster innovation-A case study of Chengdu furniture industrial cluster. Int. Manag. Rev. 2008, 4, 53-61.

27. Wei, J.; Zhu, H.Y. The contribution of networking innovation process to successful innovation within industrial clusters: Theory and its framework. In Proceedings of the 2009 International Conference on Information Management, Innovation Management and Industrial Engineering, Xi'an, China, 26-27 December 2009.

28. Du, L.J.; Zhu, Y.; Liu, Z.F. Research on independent innovation system of Chinese enterprises. In Proceedings of the 2011 International Conference on Informatics, Cybernetics, and Computer Engineering, Melbourne, Australia, 19-20 November 2011.

29. Qin, Z.H.; Li, R. An empirical study on the impact of R\&D investment and employee involvement on innovation commercialization-Evidence from it firms in China. In Proceedings of the 2013 International Conference on Management Science and Engineering 20th Annual Conference Proceedings, Harbin, China, 17-19 July 2013.

30. Gibson, C.B.; Birkinshaw, J. The antecedents, consequences, and mediating role of organizational ambidexterity. Acad. Manag. J. 2004, 47, 209-226.

31. He, Z.L.; Wong, P.K. Exploration vs. Exploitation: An empirical test of the ambidexterity hypothesis. Organ. Sci. 2004, 15, 481-494. [CrossRef]

32. Wei, G. Fuzzy evaluation of B2C E-commerce customer experience based on factor analysis. Stat. Decis. 2018, 34, 182-184.

33. Liu, J.; Jie, X. The evaluation model of entrepreneurial creative ability based on AHP method-Take the western small and medium-sized resource-based enterprises for example. Econ. Probl. 2013, 34, 67-70.

34. Zhang, W.; Zhang, Z.; Yang, Q. Study on the internal control and audit pricing-Based on the evidences of Chinese listed companies. Audit. Res. 2011, 26, 65-72.

35. Dai, W.T.; Li, W.A. Study on comprehensive evaluation model of enterprise's internal control and internal control quality of Shanghai-listed companies. Manag. Rev. 2013, 25, 128-138.

36. Li, C.; Fan, J.; Wu, M.; Liang, J. Study on enterprise cooperative technology innovation. In Proceedings of the International Conference on Service Systems and Service Management, Chengdu, China, 9-11 June 2007; pp. 1-5.

37. Leydesdorff, L. The triple helix: An evolutionary model of innovations. Res. Policy 2000, 29, $243-255$. [CrossRef]

38. Leydesdorff, L.; Etzkowitz, H. The triple helix as a model for innovation studies. Sci. Public Policy 1998, 25, 195-203.

39. Padmore, T.; Schuetze, H.; Gibson, H. Modeling systems of innovation: An enterprise-centered view. Res. Policy 2004, 26, 605-624. [CrossRef]

40. Wright, S. The roles of mutation, inbreeding, crossbreeding, and selection in evolution. In Proceedings of the Sixth International Congress on Genetics, Ithaca, NY, USA, 1 January 1932.

41. Kauffman, S.; Levin, S. Towards a general theory of adaptive walks on rugged landscapes. J. Theor. Biol. 1987, 128, 11-45. [CrossRef]

42. Chong, W.K.; Man, K.L. Examining E-Marketing Services and E-Marketing Performance with NK Model. In Proceedings of the Lecture Notes in Engineering and Computer Science, IMECS 2017, International MultiConference of Engineers and Computer Scientists 2017, Hong Kong, China, 15-17 March 2017. 
43. Auerswald, P.; Kauffman, S.; Lobo, J.; Shell, K. The production recipes approach to modeling technological innovation: An application to learning by doing. J. Econ. Dyn. Control 2000, 24, 389-450. [CrossRef]

44. Frenken, K. A complexity approach to innovation networks. The case of the aircraft industry (1909-1997). Res. Policy 2000, 29, 257-272. [CrossRef]

45. Xia, F.; Zhu, G. Study on enterprise technology innovation management-A fitness landscape approach. Sci. Sci. Manag. S. T. 2007, 28, 58-61.

46. Goodwin, B.C.; Kauffman, S.; Murray, J.D. Is morphogenesis an intrinsically robust process? J. Theor. Biol. 1993, 163, 135-144. [CrossRef] [PubMed]

47. Deng, S.J. Top Management's Cognition and Evolution of Enterprise's Dynamic Capabilities: An Empirical Study Based on the Background of Chinese Enterprises' Transformation and Upgrading. Ph.D. Thesis, Fudan University, Shanghai, China, 2010.

48. Li, X.; Shen, C.; Wang, J. Investigation on management of occupational health in large-scaled construction enterprises. China Saf. Sci. J. (CSSJ) 2013, 23, 155-160.

49. Gupta, A.K.; Smith, K.G.; Shalley, C.E. The interplay between exploration and exploitation. Acad. Manag. J. 2006, 49, 693-706. [CrossRef]

50. Lin, H.E.; Iii, M.D.; Lin, S.J.; Lin, Y.Y. Managing the exploitation/exploration paradox: The role of a learning capability and innovation ambidexterity. J. Prod. Innov. Manag. 2013, 30, 262-278. [CrossRef]

51. Boumgarden, P.; Nickerson, J.; Zenger, T.R. Sailing into the wind: Exploring the relationships among ambidexterity, vacillation, and organizational performance. Strateg. Manag. J. 2012, 33, 587-610. [CrossRef]

52. Ruiz, A.M.G.; Azkue, G.V.; Uranga, J.A. The management of innovation in the enterprise. Dyna 2011, 86, 256-259.

53. Brozovic, D. Strategic flexibility: A review of the literature. Int. J. Manag. Rev. 2018, 20, 3-31. [CrossRef]

54. Yang, J. An application of simon's theory on the architecture of complex systems. IEEE Trans. Syst. Man Cybern. 1993, 23, 264-267. [CrossRef]

55. Dong, G.; Rao, Y.S. Research on the relationship between knowledge structure and innovation performance in the complex and dynamic environment. J. Xi'an Technol. Univ. 2015, 35, 243-248.

56. Chen, T.; Zhang, J.X.; Hu, J.D. Diagnosis on control force system in large state-owned construction companies. J. Xi'an Jiaotong Univ. (Soc. Sci.) 2015, 35, 63-68.

57. Blumstein, P.; Kollock, P. Personal relationships. Ment. Welf. 1988, 14, 467-490. [CrossRef]

58. Gao, C.Y.; He, X.Y. Research on improving adaptability of htvic's knowledge innovation based on NK model. Stud. Sci. Sci. 2014, 32, 1732-1739.

59. Dahlberg, T.; Hokkanen, P.; Newman, M. Socio-technical punctuated equilibrium model enhanced with social network theory. Int. J. IT/Bus. Alignment Gov. 2017, 8, 1-16. [CrossRef]

60. Chen, T.; Huang, G.; Zhang, J.X.; Li, H. Research on control force coevolution of large construction enterprise based on self-organization theory. Stat. Inf. Forum 2016, 31, 14-20.

61. Chen, T.; Huang, G.; Yan, W.; Zhang, J.X. Research on the simulation of the growth stage for large-scale state-owned construction companies' control network. J. Xi'an Univ. Archit. Technol. (Nat. Sci. Ed.) 2016, 48, 296-302.

62. Levinthal, D.A.; March, J.G. The myopia of learning. Strateg. Manag. J. 1993, 14, 95-112. [CrossRef]

63. Anderson, J.; Calahan, C.F.; Gooding, H. Applying design thinking to curriculum reform. Acad. Med. 2017, 92, 427. [CrossRef] [PubMed]

64. Zheng, Y.; Wu, J.; Zhang, P. Streamline administration and delegate power to enterprise, enterprise vitality and enterprise innovation performance. Stud. Sci. Sci. 2017, 35, 1737-1749.

65. Delahunty, D.; Phusavat, K. Applying social enterprise concept: Exploratory study at bangkok metropolitan administration schools. In Hybrid Learning: Innovation in Educational Practices; Cheung, S.K.S., Kwok, L.F., Yang, H., Fong, J., Kwan, R., Eds.; Springer: Berlin, Germany, 2015; Volume 9167, pp. 36-45.

66. Wang, J.; Hu, L.; Ma, T. Research on the effect on enterprise's selection of innovation balance mode in alliance network: From the perspective of network structure. Stud. Sci. Sci. 2014, 32, 305-313.

67. Bo, Y.; Hong, H. Research on development path of industrial cluster innovation capability base on NK model. J. Shenyang Univ. Technol. (Soc. Sci. Ed.) 2016, 9, 202-206.

68. Schonhaar, S.; Pidun, U.; Nippa, M. Transforming the business portfolio: How multinationals reinvent themselves. J. Bus. Strategy 2014, 35, 4-17. [CrossRef]

69. Ryan, G. Systematic innovation governance for business transformation. Appita 2016, 69, 304-306. 
70. Gyun, N.S. A study on the structural relationship among entrepreneurial characteristics, success factors and performances of small business start-up founders. Manag. Inf. Syst. Rev. 2016, 35, 251-268.

71. Zhang, J.A.; Edgar, F.; Geare, A.; O'Kane, C. The interactive effects of entrepreneurial orientation and capability-based HRM on firm performance: The mediating role of innovation ambidexterity. Ind. Market. Manag. 2016, 59, 131-143. [CrossRef]

(c)

(C) 2018 by the authors. Licensee MDPI, Basel, Switzerland. This article is an open access article distributed under the terms and conditions of the Creative Commons Attribution (CC BY) license (http:/ / creativecommons.org/licenses/by/4.0/). 